\title{
Developmental Changes of the Zygomaticomaxillary Suture of the Rabbit
}

\author{
By \\ Takao TOKIOKA, Yoshikuni OHTA, Hiromi IKE and Yukiyasu SUZUKI \\ Department of Anatomy, Osaka Dental University, 1-47, Kyobashi, Higashi-ku, Osaka 540, Japan \\ (with one textfigure and 6 figures in one plate) \\ -Received for Publication, September 29, 1986-
}

Key Words: Development, Zygomaticomaxillary suture, Zygomatic bone, Maxilla, Rabbit.

Summary: Developmental changes of the zygomatic bone, maxilla and suture between them were investigated on two groups of five newborn rabbits at birth. The zygomaticomaxillary suture was not yet completed in the newborn rabbit, but its completion was observed in the first week after birth. The fusion found on the suture has gradually begun in its middle position, and finally the suture line disappeared, although rarely a remnant of the line was still observed at its inferior end even in the adult rabbit. The anterior root of the zygomatic arch was the zygomatic process of the maxilla, and the perpendicular plate of this arch was the zygomatic bone itself. The zygomatic process appeared as a trapezoid with a sharp border protruding backwards. The original suture line in the adult rabbit passed obliquely from the border anterosuperiorly up to the anterior end of the orbital margin.

General descriptions have indicated that the zygomatic bone becomes fused to the maxilla in the rabbit. However, the detailed developmental changes involved in the fusion between them, including the morphology of the zygomatic arch, have not been mentioned. The present study attempts to elucidate the formation of the suture, or fusion, and to trace the original suture line between both bone structures in the adult rabbit.

\section{Materials and Methods}

Two groups of five newborn rabbits at birth were used. The members of one of the groups of five newborns were prepared as dry skulls at birth, and at one, two, three and four weeks postnatally, while the members of the other group of five newborns were prepared at five, ten, fifteen, twenty and thirty days, respectively. In addition, ten dry skulls of adult rabbits (one-year-old) were examined.

\section{Observations}

\section{1) At birth}

The zygomatic bone (Fig. 2, a) (about 3 $\mathrm{mm}$ in width, $12 \mathrm{~mm}$ in length and $0.5 \mathrm{~mm}$ in thickness), presenting a spatula-form, had not yet united with the maxilla, so that the bones of the dry skull could be readily separated from each other. The upper margin of the zygomatic bone formed the temporozygomatic suture in its posterior portion by uniting the zygomatic process (Fig. 2, b) of the temporal bone, and extended up to the posterior border of the mandibular fossa (Fig. 2, e) since the posterior portion of the zygomatic bone was elongated in the shape of a tongue (Fig. 2, d).

The zygomatic process (Fig. 2, c) of the maxilla protruded laterally from the anterior 
end of the orbit to form the anterolateral portion of the orbital margin and also to become the anterior root (Bensley, 1948) of the zygomatic arch. The shape of this process appeared as a trapezoid expanding its lower border. Its inferior surface formed an elongated ovoid with a sharp ridge (Fig. 2, f) along the anterior and lateral margins. A deep fissure (about $1 \mathrm{~mm}$ in depth) (Fig. 3, h) found on the lateral surface of the process, passed inferoposteriorly from the superolateral end and permitted an invasion of the anteroinferior end (Fig. 3, i) of the zygomatic bone to make up the zygomaticomaxillary suture (Fig. 2, g).

\section{2) One week}

The zygomaticomaxillary suture was completed on a line around the bones. The zygomatic bone and maxilla were never separated from each other in the dry skull.

3) Two weeks

The zygomatic bone and maxilla had begun to fuse in the middle portion of their medial and lateral surfaces, so that the suture line (Fig. 4, j) had begun to disappear in the area concerned.

\section{4) Three weeks}

The fusion had progressed in the upper portion, and the suture line had begun to disappear except in the inferior one fourth (Fig. 5, k). In some individuals, however, the suture line was still observed nearer its superior end.

5) Four weeks

Almost all of the suture line had disappeared, except within a small area at its inferior end.

6) Adult

The zygomatic bone had fused completely to the zygomatic process of the maxilla with the disappearance of the suture line (Fig. 6, g), although a remnant was still observed at its inferior end (Fig. 7,1) in three of the twenty sides examined.

The zygomatic process (Figs. 6 and 7,c) of the maxilla which formed the anterior root of the zygomatic arch had expanded inferolaterally from the anterior end of the orbital margin, while its inferolateral margin had become sharpened (Figs. 6 and 7, f), and its anterior tip (Figs. 6 and 7, m) protruded forwards distinctly (masseteric spine of Bensley, 1948, spina facialis of Tsusaki, 1954, tuber faciale of Barone et al., 1973).

\section{Discussion}

The zygomaticomaxillary suture was completely formed in the first week after birth, although it did remain incomplete in the newborn. The fusion on the suture began to find at the middle of both medial and lateral surfaces. The suture line thus disappeared gradually through superior and inferior progression of the fusion. However, a remnant of the suture was rarely found at its inferior end in the adult.

Tsusaki (1954) indicated the zygomatic process of the maxilla as the zygomatic bone by mistake. The make-up of the zygomatic arch may be appropriate to the description in Bensley's textbook (1948) as judged from the observations with aging performed in the present study. The anterior root of the zygomatic arch, as mentioned by Bensley, was the zygomatic process of the maxilla and the perpendicular plate was the zygomatic bone itself. The ventral corner of the zygomatic process was named the protruding, masseteric spine by Bensley and the tuber faciale by Barone et al. (1973). However, the present authors confirmed that only this anteriorly protruding protion indicated by the previous scholars did not represent the entire zygomatic process of the maxilla, but it can be said that this process really was the trapezoid with a sharp margin continuing backwards from this protrusion.

The suture line may originally pass obliquely anterosuperiorly from the posterior end of the sharp margin mentioned 
above in front of a depression on the lateral surface of the zygomatic arch and reach the posterior end after bending posteromedially through the anterior end of the orbital margin (Fig. 1).

\section{Literature cited}

1) Barone, R., C. Pavaux, P. C. Blin and P. Cuq: Atias of rabbit anatomy. 8-10, 44. Masson \& C., Paris, 1973.

2) Bensley, B. A.: Practical anatomy of the rabbit. 8th ed., 174, 192, 193. Blakiston Co., Phila., 1948.

3) Tsusaki, T.: Anatomy of the laboratory animals. Vol. 1, Rabbit, 25, 26. Kanehara Co., Tokyo, 1954 (in Japanese). 


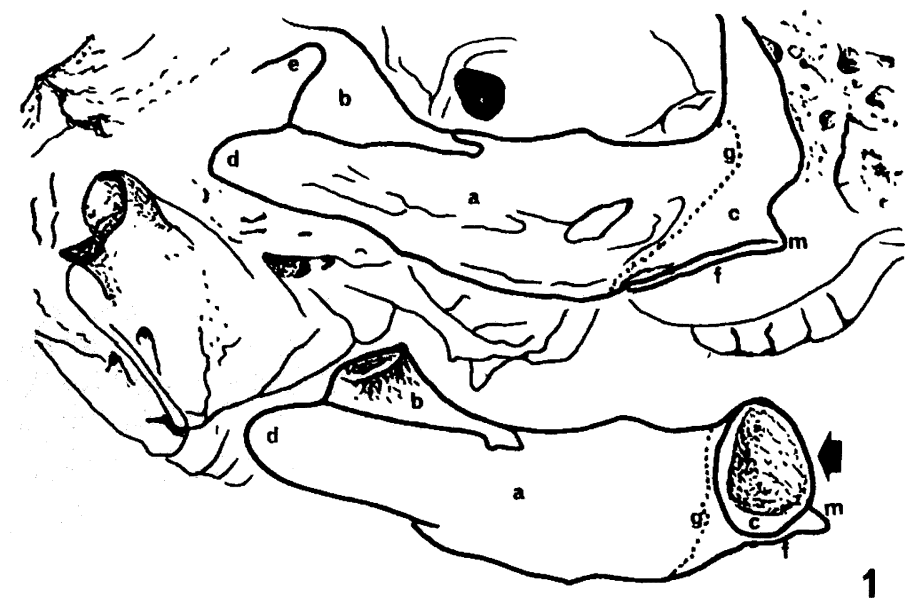

Fig. 1. Schematic drawing from Fig. 6 .

(g) A supposed original su ture line.

\section{Guide to Abbreviations}

\footnotetext{
a: Zygomatic bone

b: Zygomatic process of the temporal bone

c: Zygomatic process of the maxilla

d: Elongated, posterior portion of the zygomatic bone

e: Mandibular fossa

f: Sharp ridge along the anterior and lateral margins of the zygomatic process of the maxilla

g: Zygomaticomaxillary suture
}

$\mathrm{h}$ : Deep fissure on the zygomatic process of the maxilla

i: Anteroinferior end at the zygomatic bone

$\mathrm{j}$ : Suture line before disappearance

$\mathrm{k}$ : Remaining suture line

1: Remanant suture line of the inferior end

$\mathrm{m}$ : Anterior tip of the zygomatic process of the maxilla

$\stackrel{\leftrightarrow}{\rightarrow} \quad$ Medial surface of the opposite zygomatic arch

\section{Explanation of Figures}

\section{Plate I}

Figs. 2 and 3. Newborn. Lateral view of the zygomatic arch of the right side. $\times 3.3$ and $\times 6.6$, respectively.

In Fig. 3, the zygomatic bone is moved backwards from the zygomaticomaxillary suture.

Fig. 4. Two-week-old. Lateral view of the left side. $\times 3.3$.

Fig. 5. Three-week-old. Lateral view of the right side. $\times 3.3$.

Figs. 6 and 7. Adult rabbit. Lateral view of the right side. $\times 2.2$ and $\times 3.3$, respectively. 
Zygomaticomaxillary Suture of Rabbit $\quad 391$

Plate I
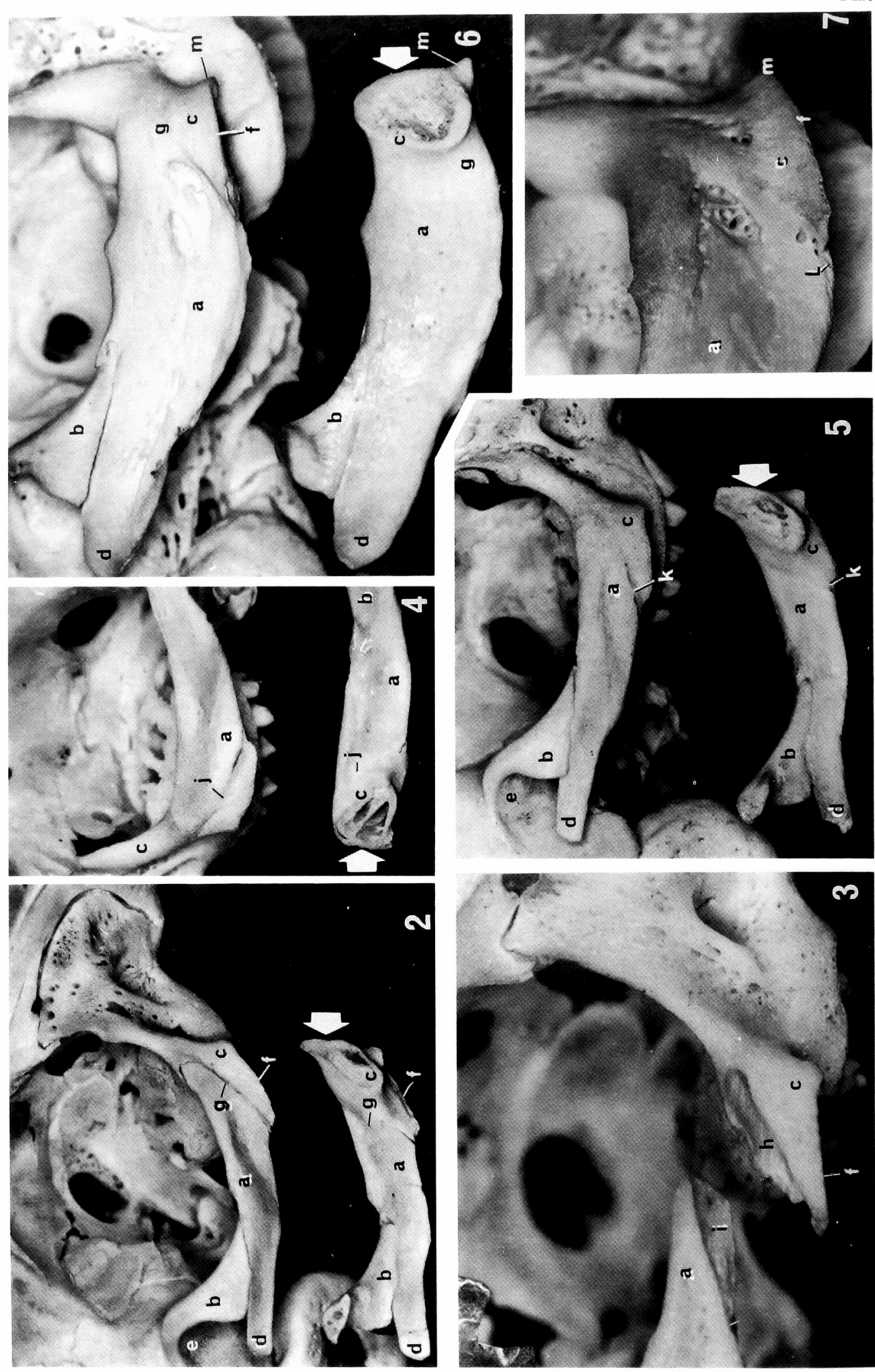